\title{
Tsafon
}

Revue d'études juives du Nord

$75 \mid 2018$

Exil des langues - Langues d'exil

\section{Universalité de Hayim Gouri (1923-2018)}

\section{Michèle Tauber}

\section{OpenEdition}

\section{Journals}

Édition électronique

URL : https://journals.openedition.org/tsafon/647

DOI : $10.4000 /$ tsafon. 647

ISSN : 2609-6420

\section{Éditeur}

Association Jean-Marie Delmaire

\section{Édition imprimée}

Date de publication : 1 juin 2018

Pagination : 151-156

ISSN : 1149-6630

\section{Référence électronique}

Michèle Tauber, "Universalité de Hayim Gouri (1923-2018)», Tsafon [En ligne], 75 | 2018, mis en ligne le 06 mai 2019, consulté le 01 juillet 2021. URL : http://journals.openedition.org/tsafon/647 ; DOI https://doi.org/10.4000/tsafon.647 


\section{Hommage}

\section{Universalité de Hayim Gouri (1923 - 2018)}

\section{Michèle Tauber*}

Né en 1923 à Tel-Aviv, en Palestine mandataire, Gouri est à la fois poète, écrivain, journaliste, traducteur et cinéaste. En 1941, après avoir achevé ses études dans un lycée agricole, il s'engage dans le Palmah armé de la Haganah, organisation clandestine juive qui luttait contre les Britanniques pour l'indépendance. En mai 1947, il est envoyé par le Palmah en Europe, afin de rapatrier les rescapés de la Shoah. Revenu en Israël après la création de l'État en mai 1948, il participe à la guerre d'indépendance israélo-arabe en 1948-1949. Il étudie la littérature hébraïque, la philosophie et le français à l'université hébraïque de Jérusalem, puis part compléter son diplôme à Paris pendant un an à la Sorbonne (1952). Il participe également à la guerre des Six Jours (1967) et à celle de Kippour (1973). Si à la suite de la réunification de Jérusalem et l'annexion de territoires de Cisjordanie en 1967, Gouri partage l'exaltation générale qui gagne le pays et devient un ardent supporter du « Grand Israël », il revient sur ses positions et adopte dans les années quatre-vingts un point de vue beaucoup plus modéré. Il reconnaît luimême cette remise en question permanente : "Toute ma vie, j'ai été

\footnotetext{
${ }^{*}$ Université Paris 3 - Sorbonne nouvelle et Institut universitaire Élie Wiesel.
} 
déchiré entre la pitié, l'amour de l'autre, et l'obligation d'agir, de me battre... ${ }^{1}$.

Son œuvre inclut de la poésie, de la prose, des essais, des articles de fond journalistiques, des films et des traductions. Son premier recueil de poésies, Les fleurs du feu (Pirhé ha-esh) paraît en 1949 en pleine guerre d'indépendance; il devient l'ouvrage le plus populaire de la littérature sur la guerre : certains de ses poèmes, déclamés ou mis en musique, entrent dans le canon des commémorations en Israël et deviennent des hymnes nationaux non officiels. Par sa biographie, son apparence physique et le fait d'être tout à la fois un homme du livre et un combattant, Gouri est considéré comme le poète emblématique de la "génération du Palma $\underline{h}$ " et ses poèmes figurent dans toutes les anthologies poétiques. Par son œuvre, comme par ses interventions publiques, il incarne une certaine conception d'Israël et du sionisme, celle du sabra tourné vers l'avenir sans renier le passé, aimant sa terre et son peuple et prêt à se battre pour eux, aspirant à la paix sans devenir pacifiste, homme de gauche resté fidèle au consensus sioniste.

Il n'en demeure pas moins très marqué par le conflit israélopalestinien et déclare: "Je suis une guerre civile». Dans ce même poème, Guerre civile, il ajoute : «Une moitié de moi fusille l'autre au mur des vaincus... ». On retrouve l'un de ses textes dans une anthologie de poèmes pacifistes arabes et juifs ${ }^{2}$. Si l'épouvante de la guerre est souvent évoquée, les premiers recueils chantent aussi l'amour et le poète y entrelace l'amour de la femme et celui de la terre natale. Le motif principal en est la marche : le narrateur ou le récitant est en mouvement perpétuel à travers l'espace israélien ou étranger tout en étant fortement enraciné dans un récit biographique bien concret. Dans sa poésie plus tardive, ces voyages deviennent des quêtes spirituelles plus intimes. Avec l'avènement des poètes de la «génération de l'État» dans les années cinquante, Gouri prend lui aussi le virage de la modernité et commence à écrire dans une langue familière, avec un rythme plus libre et des métaphores empruntées au quotidien. De même, le pathétique se mue en ironie lorsqu'il abandonne l'identification aux valeurs collectives pour exprimer le désir d'être un «individu » et de vivre en tant que tel. Ainsi

\footnotetext{
${ }^{1}$ Moshé Granot, «J'ai absorbé en moi toutes les contradictions : conversation avec Hayim Gouri », Conversations avec des écrivains, Qavim, Tel-Aviv, 2007, p. 101-122.

${ }^{2}$ Jacques Eladan (dir.), Espérance poétique : chalom-salam - Anthologie de poètes pacifistes juifs et arabes de l'Antiquité à nos jours, Paris, L'Harmattan, 1997, cf. p. 40 : « Nos corps étendus ».
} 
semblable à Ulysse dans son poème éponyme, le récitant revient chez lui, «Errant, las, tel un rêveur, rongé de nostalgie, parmi des gens qui parlaient un autre grec $»^{3}$.

Mais Hayim Gouri n'est pas seulement le représentant du jeune État d'Israël et de ses jeunes gens, il est aussi celui qui, en 1947, est envoyé par la Haganah en Europe, pour y organiser l'émigration de rescapés de la Shoah. Il a décrit cet épisode marquant de sa vie dans un entretien à $L^{\prime} \operatorname{Express}^{4}$ :

\begin{abstract}
Hongrie, Tchécoslovaquie, Autriche... C'était ma première rencontre avec mes frères inconnus, les Juifs d'Europe. Ce fut le grand changement de ma vie. À Budapest, dans une synagogue, j'ai entendu un rabbin prononcer cette phrase de la Genèse : "C'est mon frère que je cherche...» Tout le monde s'est mis à pleurer. Je me suis demandé : « Gouri, qui es-tu ? » J'ai compris que j'appartenais à un peuple assassiné, un peuple millénaire que l'on appelle «juif». En Israël, j'étais un hébreu. Je me suis découvert juif... J'avais quitté la Palestine avec un passeport britannique. Je revenais Israélien, avec un avion rempli d'armes livrées par la Tchécoslovaquie. Tout était changé. Au moment où les rescapés de la Shoah arrivaient, la jeunesse israélienne se faisait tuer à la guerre. Pouvait-on aussi envoyer au combat les derniers enfants des familles exterminées dans les camps ? Mais, pour eux, il s'agissait d'effacer l'humiliation de la Shoah. Ils revivaient en combattants, et non plus en victimes. Israël est né à cause de la Shoah, entend-on parfois. Non: malgré la Shoah! Que nous soyons le seul peuple au monde auquel on refuse la souveraineté, cela nous était inacceptable.
\end{abstract}

À partir des années soixante, Gouri consacre une partie de son œuvre à la Shoah. Le sentiment de culpabilité de l'Israélien, arrivé trop tard au secours de ses frères en Europe, le conduit à analyser en détail le procès Eichmann qu'il couvre en tant que journaliste pour le quotidien La-merhav. Il publie ses chroniques sous le titre Face à la cage de verre ${ }^{5}$ (1962). Les minutes du procès sont décrites du point de vue du sabra qui s'efforce de comprendre l'horreur qui lui est révélée et d'exprimer l'inexprimable. Ce livre a eu un impact essentiel sur la société israélienne de l'époque et sa vision de la diaspora et des rescapés de la Shoah. Certes le procès en lui-même incarne un tournant pour Israël mais le livre de Gouri a contribué à façonner une nouvelle mentalité, une approche beaucoup plus empathique vis-à-vis des Juifs d'Europe qui avaient survécu. La force et la nouveauté de ce compte rendu résident dans le

\footnotetext{
${ }^{3}$ Anthologie de la poésie en hébreu moderne, Paris, Gallimard, 2001, p. 208.

${ }^{4}$ Interview de Dominique Simonnet le 9 mars 2006.

${ }^{5}$ Traduit de l'hébreu par R. Cidor, Paris, Éditions Tirésias, 1995 ( $1^{\text {ère }}$ éd. La cage de verre, Paris, Albin-Michel, 1964).
} 
mélange des témoignages, des documents écrits, des problèmes du moment exposés dans un style poétique très personnel.

Dans ce procès-témoin, pour la première fois, l'État d'Israël avait la possibilité de se confronter avec un terrible chapitre de l'histoire des Juifs. Tout d'un coup, le pays a donné la parole à des gens murés dans le silence depuis plus de treize ans. Quand ils ont ouvert la bouche, ce fut un bouleversement pour la jeune génération israélienne. Ce fut aussi le moyen de comprendre sa véritable identité, née de ce mélange d'Israël et d'un peuple et massacré. ${ }^{6}$

En 1965, Gouri publie son roman L'affaire chocolat ${ }^{7}$ où il dépeint deux rescapés de la Shoah de retour dans leur ville après la guerre. L'un est un intellectuel qui ne peut se libérer des souvenirs du passé et son compagnon tente par toutes sortes de stratagèmes de revenir à l'existence d'avant et de faire revivre ce qui n'est plus : «Je veux faire un grand bond et partir ailleurs. Continuer de marcher. Leur montrer. Je continue de vivre. Tu vois. Je ne suis pas mort. On ne m'a pas volé mon nom ${ }^{8}$.

Entre 1974 et 1983 Hayim Gouri dirige une équipe cinématographique afin de procéder au montage d'une trilogie documentaire relatant l'histoire de la Shoah, à partir de l'accession au pouvoir des nazis jusqu'à la destruction des Juifs d'Europe, les révoltes, la fuite hors d'Europe et l'immigration clandestine en Palestine mandataire. Les trois films Le quatre-vingt-unième coup, Flammes dans la cendre et Les portes de la mer présentent successivement, avec des images d'archives non professionnelles et de nombreux témoignages, le processus d'extermination, les premières révoltes des ghettos et des camps et le sauvetage, dans l'Europe exsangue, de centaines de rescapés.

En 1988, dans le recueil Compte courant, Gouri se présente comme un poète à l'identité double : il est à la fois le lien cananéen, antique, du « fils de la terre d'Israël », issu des matériaux du lieu et l'incarnation des événements qui l'ont forcé à comprendre son appartenance au monde de ses ancêtres en diaspora et à l'histoire du peuple juif et de sa culture. À la question posée par Dominique Simonnet : «Qui es-tu Gouri ? », le poète répond :

«Je suis israélien ». Qu'est-ce que cela veut dire ? Les uns ont affirmé qu'Israël est un État juif, d'autres qu'il est l'État des Juifs. Dans ce peuple bizarre, où se

\footnotetext{
${ }^{6}$ Interview dans L'Humanité, 12 avril 1996.

${ }^{7}$ Traduit de l'hébreu par Rosie Pinhas-Delpuech, Paris, Denoël, 2002.

${ }^{8}$ L'affaire chocolat, Paris, Denoël, 2002, p. 74.
} 
trouve la frontière entre le religieux et le national ? Dans mon identité est incluse mon appartenance au peuple juif millénaire, celui de l'époque biblique. Mais je suis lié à toutes les nations qui ont vécu sur cette terre, les Turcs, les Mongols, les Byzantins, les Romains et les Arabes.

En août 2008, à la mort du poète palestinien Mahmoud Darwich, Gouri écrit un texte à sa mémoire dans le quotidien israélien Ha-Arets. À ses yeux, Darwich est le plus grand poète palestinien, le poète national. Il a lu sa poésie et ressent une vive empathie avec les descriptions des paysages palestiniens aujourd'hui disparus: le chêne et la vigne, le figuier et l'olivier, la citerne et le puits, les parfums et les éléments. Mais Gouri a cessé de croire au rêve de sa jeunesse, à un État fraternel israélien et arabe :

Il faut nous séparer. Deux États pour deux nations. Parfois je pense que cette situation ne finira jamais. Et parfois je me dis que les deux peuples sont plus sages qu'autrefois, que même si l'avènement au pouvoir du Hamas semble nous ramener en 1947, on renouera le dialogue... Il y a une immense fatigue des deux côtés. Nous sommes fatigués de la mort. Mais il ne s'agit pas d'une malédiction ni d'une punition des cieux. C'est une affaire humaine, banalement humaine. Un ami arabe m'a dit un jour : «Vous, les Juifs, vous cultivez l'idée d'un avenir salvateur, où on passerait de l'obscurité à la lumière, de la guerre à la paix. Pour nous, le temps est cyclique : été, printemps, hiver, automne ; guerre, paix, amour, haine. Alors, n'attendons pas. Donnons seulement à la vie la chance d'être vécue ». Je crois qu'il a raison: juste amoindrir la haine, donner une petite chance à la vie. $^{9}$

Hayim Gouri est également un amoureux de la langue française qu'il pratique couramment. Il a traduit en hébreu des œuvres de Charles Baudelaire, Arthur Rimbaud, Guillaume Apollinaire, Paul Claudel, Georges Duhamel, Marcel Pagnol et a reçu de nombreux prix littéraires dont le prestigieux prix Israël pour l'ensemble de son œuvre. Voici la traduction de l'un de ses poèmes les plus célèbres où se conjuguent les diverses strates de l'histoire et de la langue hébraïque, de la Bible à nos jours :

Le bélier vint le dernier.

\section{Héritage}

Et Abraham ne savait pas qu'il répondait à la question de l'enfant, Prémices de sa vigueur au déclin de sa vie.

\footnotetext{
${ }^{9}$ L'Express, 9 mars 2006.
} 
Il leva sa tête blanchie.

Comme il voyait qu'il ne rêvait pas

et que l'ange était là -

le couteau glissa de sa main.

L'enfant libéré de ses liens

vit le dos de son père.

Isaac, dit le récit, ne fut pas sacrifié.

Il vécut longtemps,

fut heureux, puis faiblit la lumière de ses yeux.

Mais il légua cette heure-ci à ses descendants.

Ils naissent

un couteau dans le cœur ${ }^{10}$.

Hayim Gouri, auteur aux multiples facettes, engagé simultanément en littérature et en amour pour sa terre et son peuple, correspond bien à la figure de l'écrivain par excellence. L'évolution dans son écriture, les changements et revirements dans ses positions politiques ne renvoient pas l'image d'une icône patriotique immuable mais en font un artiste aux dimensions humaines auquel peuvent s'identifier les générations successives. Ainsi la stature de l'écrivain ne devient véritablement nationale que lorsqu'elle dépasse les contingences étriquées du quotidien et accède à l'universel.

\footnotetext{
${ }^{10}$ Traduction : Charlottte Wardi, Anthologie, op. cit., p. 207.
} 